\title{
Avoiding Radiation Risks from Dental Cone-beam Computed Tomography Imaging in Orthodontic Patients
}

\author{
Abdallah S. Nouh ${ }^{1 *}$, Abdel Majeed H. M²., Essam Mohamed Nassef Selim² \\ ${ }^{(1)}$ Nuclear and Radiological Regulatory Authority, (NRRA), Cairo, Egypt \\ ${ }^{(2)}$ Department of Orthodontics, Faculty of Oral and Dental Medicine, Future University, Cairo, Egypt
}

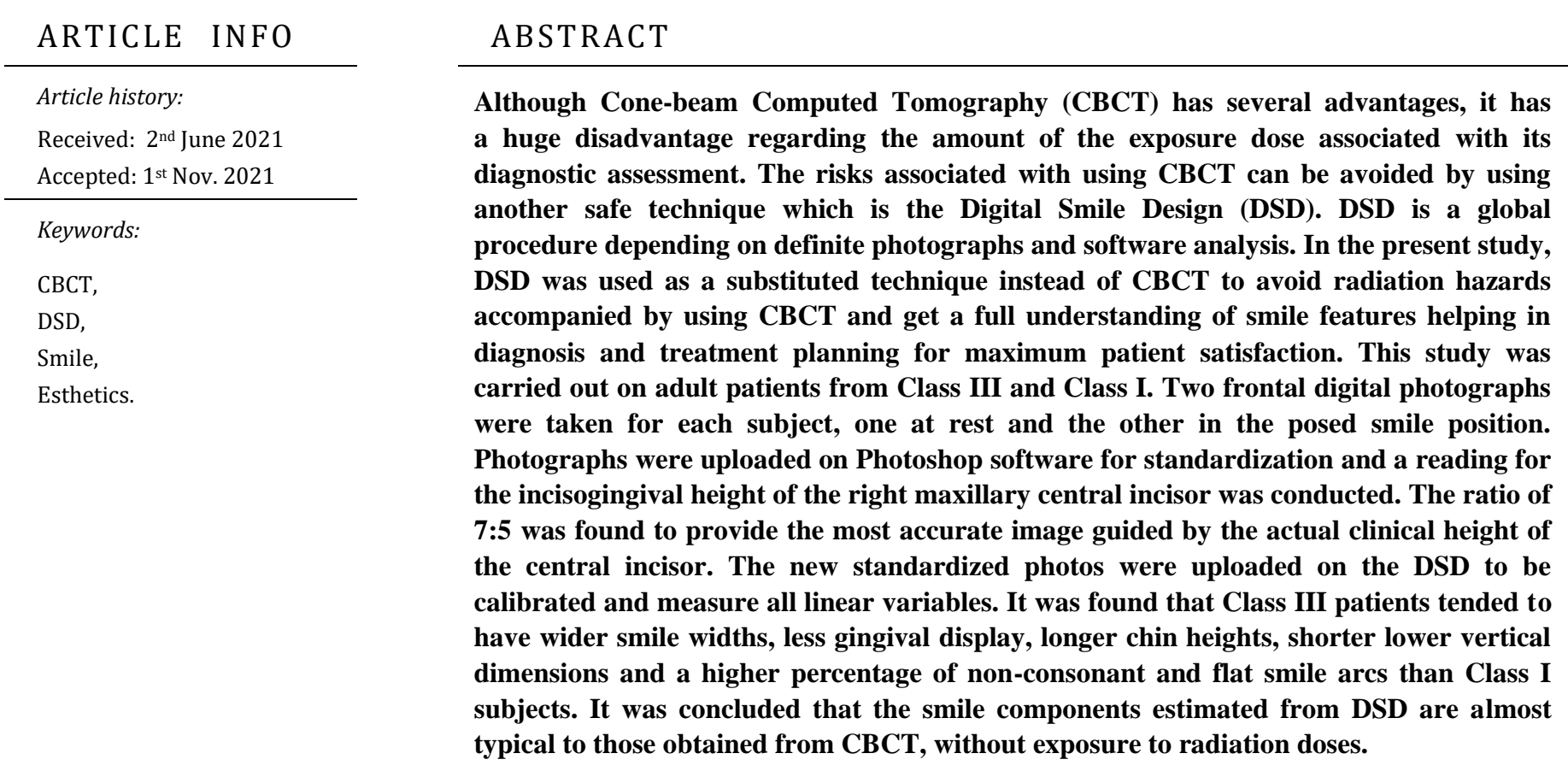

Smile esthetics has become the main focus of patients seeking orthodontic treatment. Now smile analysis represents an essential requirement in present orthodontic treatment planning that permits distinguishing positive and negative basics in a patient's smile [1]. The smile has an essential responsibility in social interaction. It assigns various positive emotions including pleasure, endorsement, and humor. Esthetically pleasant smile might enhance the selfconfidence in social positions [2]. Dentofacial beauty is mainly significant to a person's psychosocial well being, where persons with a regular dental look seem more socially nice-looking than those with malocclusions. Those with deprived dental esthetics have been related to need of self-confidence and are considered to be disadvantaged in social, educational, and occupational settings [3].
In order to design a diagnostic plan and hence a treatment plan, accurate measurements should be done. This can be achieved by performing CBCT based on the dentist's request. CBCT strategy is an ordinary and accessible approach that is used for medical indications in dental diagnosis $[4,5]$. CBCT proved to be a useful technique, especially in hard tissues imaging in dentistry, as it provides a three dimensional image. Some authors reported that CBCT can be used to get exact analysis of skeletal irregularity, easier position of crashed teeth, enhanced surgical plans, and better discovery of pathologies by using dental CBCT $[6,7]$.

Although CBCT has several advantages, it still has enormous disadvantages concerning the quantity of exposure dose associated with diagnostic CBCT assessment. Roberts et al. had pointed out that the amount of exposure dose delivered from CBCT is higher 
than the dose delivered from classic panorama radiography by 5-16 times [8]. Al Najjar et al. have concluded that the equivalent radiation doses associated with CBCT examination are extensively high for the neck organs in children and adults [9]. This means that dentists must use one of the various procedures that are used to estimate the effective doses associated with CBCT examination and can be inserted into the anthropomorphic phantoms. For example, they can use TLD dosimeter [10] or optical stimulated luminous dosimeter [11] which gives a rapid reading. These procedures need many stages not only for information achievement, but also to comprise major doubts [12].

The risks associated with the use of CBCT can be avoided by the use of another safe method which is the Digital Smile Design (DSD). DSD is an orderly global procedure which is dependent on definite photographs and software analysis. It assists the dentists to generate and develop a route of treatment, particularly in multidisciplinary approaches. Moreover, it supplies a virtual simulation of the concluding results. In addition, it allows communications between the dental team and the patients. An additional feature of DSD which enables analysis of the scope and aesthetics of teeth, smile and face, and allows the feasibility of enhancing the certainty of concluding plan outcome [14].

Several studies had evaluated smile features and their influences on attractiveness. Rashed and Heravi [15] evaluated the impact of different malocclusions (Class I, II and III) on lip-tooth relationships during smiling using video images. Malhotra et al [16] studied the effect of specific facial hard and soft tissues on smile characteristics. It was observed that the analysis and getting average for different smile components provide a strategy for the construction of an esthetic smile. In the present study, the authors used DSD as a substitute technique rather than $\mathrm{CBCT}$ to achieve perfect orthodontic outcome concerning the smile features that help in diagnosis and treatment planning for maximum patient satisfaction.

\section{EXPERIMENTAL}

The study was carried out on 30 skeletal Class III and Class I patients adult subjects with average vertical facial patterns. In a previous study by Kakadiya $\mathrm{J}$ et al [17], the response within skeletal Class I and III groups was normally distributed true difference between the study groups was 1.42 .
Sample size calculation indicated that for a study with a power of $80 \%$ and an alpha error of 0.05 , the minimum estimated sample size was 9 cases per group for a total of 18 cases. 30 patients were included in the current study for possible dropouts, which were equally divided into two groups which included 15 adult patients for each group. Subjects included in the study had an average age of 18-30 years in order to minimize the effects of growth on facial appearance as reported by Leonardi et al [18]. Patients with skeletal class III and class I facial profiles with average vertical facial pattern, full set of permanent dentition who had not received any pervious orthodontic treatment, while those with congenitally missing, malformed or extracted teeth, having fixed bridges or crowns visible on smiling, excessive dental attrition, lip irregularity or history of lip surgery and facial asymmetries were excluded from the study. Two frontal photographs at rest and posed smile were taken by a Canon G11 camera set on a tripod from a fixed distance of 1.5 meters where the camera was focused on the mouth showing from the nose to the chin. The camera lens was adjusted to be parallel to the floor by adjusting the mount-head of the tripod guided by the leveling indicator that is built in the tripod. Photographs were taken for each patient in the natural head position. The head was held in an upright posture and eyes were focused on a point in the distance at eye level such that the visual axis was horizontal.

The Digital Smile Design software program was used for measuring smile variables. Standardization was mandatory to avoid any magnification errors where the incisogingival height of the right maxillary central incisor was clinically measured (actual height) for each case using a vernier caliper to the nearest $0.1 \mathrm{~mm}$. Photographs were uploaded on Photoshop software for standardization and a reading for the incisogingival height of the right maxillary central incisor which was done where a ratio of 7:5 was found to provide the most accurate image guided by the actual clinical height of the central incisor. The new standardized photos were uploaded on the Digital Smile Design software (DSD) to be calibrated to measure all linear variables in to the nearest $0.1 \mathrm{~mm}$. The actual incisogingival height in millimeters was used for automatic calibration by the digital smile system (DSS) (Figures $1 \& 2$ ), where twelve smile components were evaluated at rest and on smiling. 


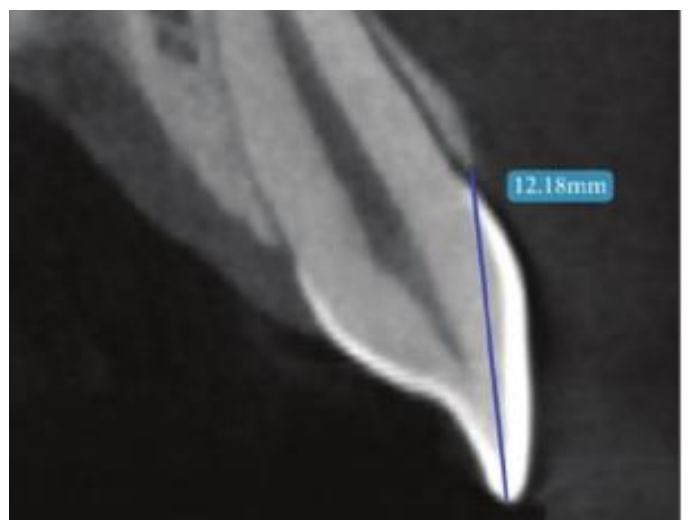

Fig. (1): Incisogingival height of the Maxillary incisors using CBCT cited by Khamis and Abdelrehim [19]

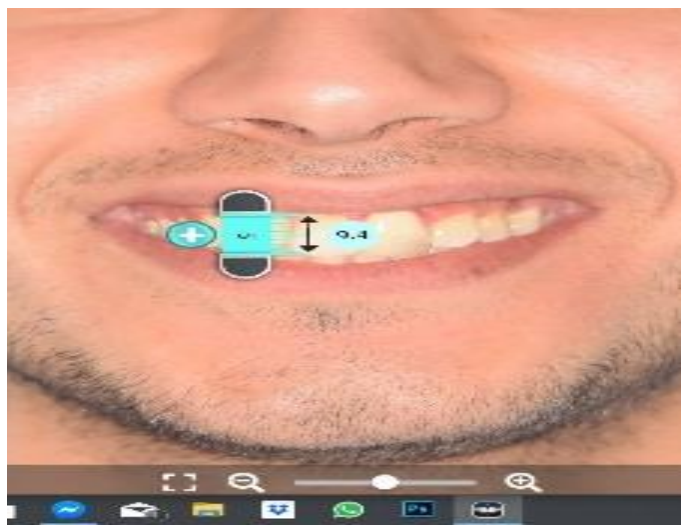

Fig. (2): Measuring incisor height using digital smile design (DSD)

The smile components measured at rest are: Upper lip length which is the distance between the base of the nose (Subnasale) and the inferior part of the upper lip (Stomion superius) $\left(\right.$ Stom $\left._{\mathrm{s}}\right)$, (2) Upper lip thickness which is the vertical distance from the most superior point of the cuspid's bow to the most inferior portion of the tubercle of the lower lip. (3) Intercomissure width which is the horizontal distance between two parallel lines extending vertically from the corners of the mouth, (4) Lower facial height which is the vertical distance between Subnasale (Sn) to soft tissue Menton (Me'), (5) Lower lip thickness which is the vertical distance between Stomion (Stom) to Labrale inferius (Li), (6) Lower lip length which is the vertical distance from Stomion (Stom) to Sulcus inferius (Si), and (7) Chin height which is the vertical distance from Sulcus inferius ( $\mathrm{Si}$ ) to soft tissue Gnathion (Gn').

While the smile components measured on smiling are: (8) Smile width which is the horizontal distance between the left outer commissure to the right outer commissure of the lips on smiling, (9) Maxillary Incisor display which is the amount of vertical tooth exposure during smiling, (10) Buccal corridor which is the distance between the most distal maxillary dentition and the commissure, (11) Gingival display which is the amount of maxillary gingival exposure between inferior border of upper lip and marginal gingiva of maxillary central incisors in $\mathrm{mm}$ and (12) Smile arc which is the relationship of the curvature of the incisal edges of the maxillary incisors and canines to the curvature of the lower lip in the posed smile.

\section{STATISTICAL ANALYSIS}

Numerical data were investigated for normality by checking the distribution of data and via tests of normality (Kolmogorov-Smirnov and Shapiro-Wilk tests). All data exhibited normal (parametric) distribution except for the gingival display which showed nonnormal (non-parametric) distribution. Data are presented as means, standard deviation (SD), mean difference and 95\% Confidence Interval (95\% CI) for the difference values. For parametric data, Student's t-test was used to compare between the two Classes. For non-parametric data, Mann-Whitney $U$ test was used to compare between patients of both Classes. The significance level was set at $\mathrm{P} \leq 0.05$. Statistical analysis was performed with IBM SPSS Statistics for Windows, Version 23.0. Armonk, NY: IBM Corp. All measurements were repeated for 10 frontal photographs at two different occasions by the main observer where there was good to very good intra-observer reliability (agreement) regarding all measurements with Cronbach's alpha values ranging from 0.614 to 0.862 .

\section{RESULTS}

Means, standard deviation (SD), 95\% Confidence Interval $(95 \% \mathrm{CI})$ and results of student's t-test for comparison between esthetic soft tissue measurements for Class III and I patients at rest and on smiling are presented in Tables (1\&2). The frequencies, percentages (\%) and results of Fisher's exact test for comparison between smile arcs of Class I and Class III patients on smiling are shown in Table (3).

At rest, the upper lip length $(19.72 \mathrm{~mm}+2.03)$, intercommissural distance $(52.08 \mathrm{~mm}+6.04)$ and the lower facial height $(61.65 \mathrm{~mm}+6.31)$ were found to be significantly longer for skeletal Class I patients as compared to Class III patients. On the other hand, the chin height $(43.9+5.32)$ was notably longer for Class III patients relative to Class I. There was an insignificant difference for the lower lip length, upper and lower lip thickness between both groups (Figure 3 and Table 1). 
On smiling, the gingival display of Class I patients was found to be significantly greater $(3.20 \mathrm{~mm}+2.15)$ than that for Class III patients $(1.03 \mathrm{~mm}+2.31)(P$-value $=0.008$, Effect size $=0.988)$. On the other hand, the smile width was significantly wider for skeletal Class III patients $(77.55 \mathrm{~mm}+13.16)$ compared to Class I patients $(68.68 \mathrm{~mm}+6.24)(P$-value $=0.026$, Effect size $=0.861)$. Statistically insignificant differences were found for maxillary incisor display and buccal corridors between both groups (Figure 4 and Table 2).

Table (1): A comparison between soft tissue measurements of Class I and Class III patients at rest

\begin{tabular}{|c|c|c|c|c|c|c|c|c|c|}
\hline \multirow{2}{*}{ Measurement (mm) } & \multicolumn{2}{|c|}{$\begin{array}{c}\text { Class I } \\
(\mathrm{n}=15)\end{array}$} & \multicolumn{2}{|c|}{$\begin{array}{c}\text { Class III } \\
(\mathrm{n}=15)\end{array}$} & \multirow{2}{*}{$\begin{array}{c}\text { Mean } \\
\text { Difference } \\
(\mathrm{mm})\end{array}$} & \multicolumn{2}{|c|}{ 95\% CI for Difference } & \multirow{2}{*}{$P$-value } & \multirow{2}{*}{$\begin{array}{l}\text { Effect size } \\
\text { (d) }\end{array}$} \\
\hline & $\begin{array}{l}\text { Mean } \\
(\mathrm{mm})\end{array}$ & SD & $\begin{array}{l}\text { Mean } \\
(\mathrm{mm})\end{array}$ & SD & & $\begin{array}{l}\text { Lower } \\
\text { bound }\end{array}$ & $\begin{array}{l}\text { Upper } \\
\text { bound }\end{array}$ & & \\
\hline \multicolumn{10}{|l|}{ At rest } \\
\hline Upper lip length & 19.72 & 2.03 & 16.44 & 2.17 & 3.28 & 1.71 & 4.85 & $<0.001 *$ & 1.561 \\
\hline Upper lip thickness & 6.29 & 1.18 & 6.14 & 1.49 & 0.15 & -0.85 & 1.16 & 0.757 & 0.112 \\
\hline $\begin{array}{l}\text { Inter-commissural } \\
\text { distance }\end{array}$ & 52.08 & 6.04 & 40.47 & 3.44 & 11.61 & 7.94 & 15.29 & $<0.001 *$ & 2.362 \\
\hline Lower facial height & 61.65 & 6.31 & 52.31 & 4.88 & 9.34 & 5.13 & 13.56 & $<0.001^{*}$ & 1.656 \\
\hline Lower lip thickness & 16.20 & 2.04 & 15.93 & 2.46 & 0.27 & -1.43 & 1.96 & 0.749 & 0.118 \\
\hline Lower lip length & 23.9 & 1.93 & 22.47 & 3.76 & 1.43 & -0.8 & 3.67 & 0.199 & 0.480 \\
\hline \multirow[t]{2}{*}{ Chin height } & 37.09 & 3.76 & 43.93 & 5.32 & 6.84 & -10.29 & -3.4 & $<0.001^{*}$ & 1.486 \\
\hline & \multicolumn{9}{|c|}{ *: Significant at $P \leq 0.05$} \\
\hline
\end{tabular}

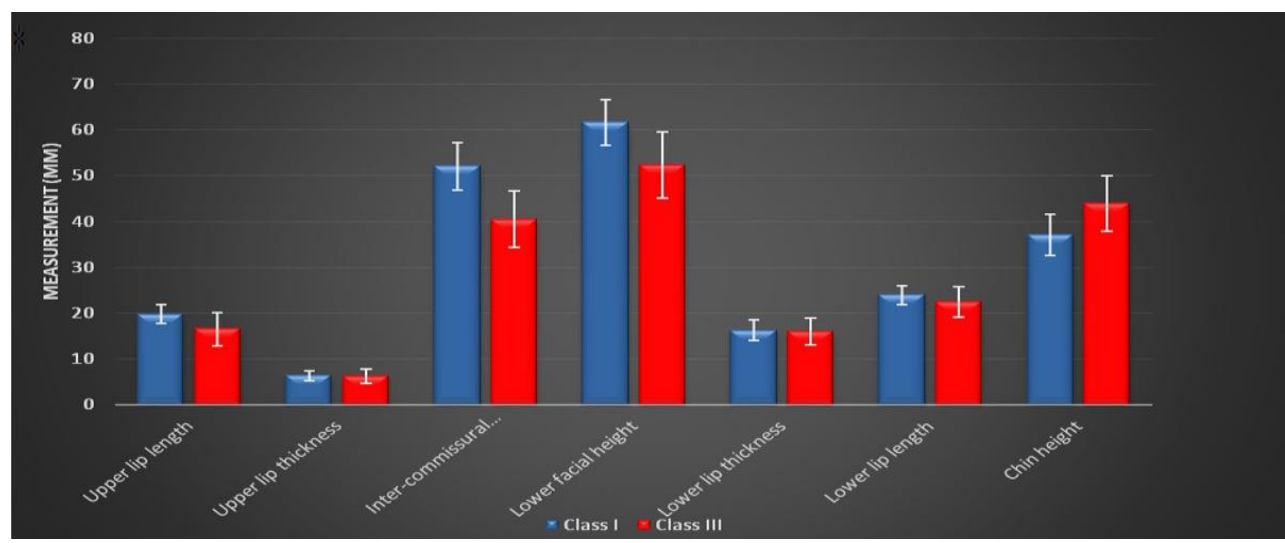

Fig. (3): Bar chart representing mean values for soft tissue measurements of Class I and Class III patients at rest

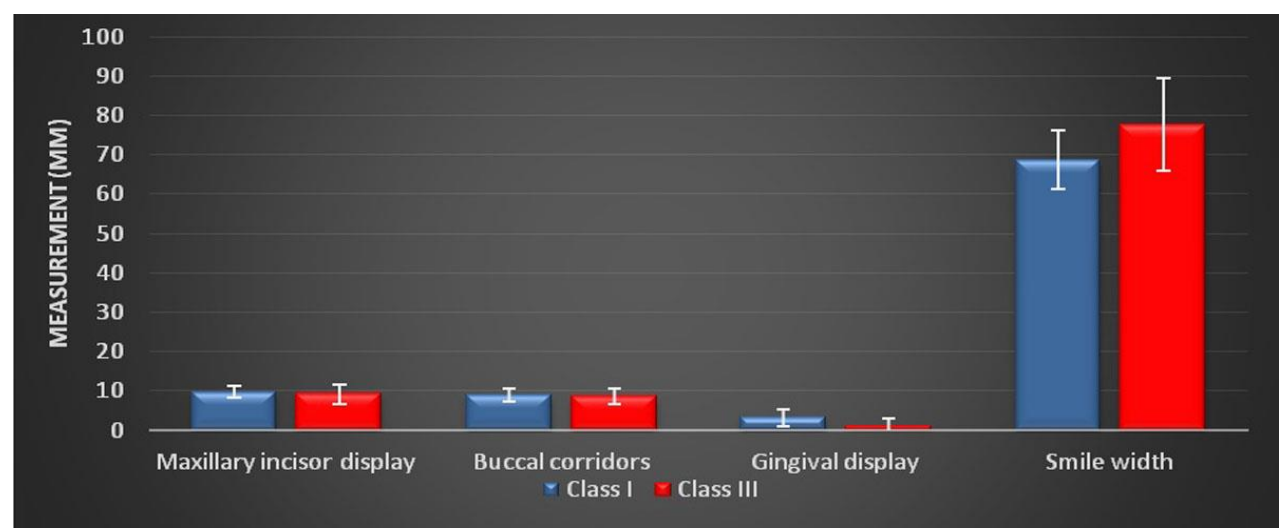

Fig. (4): Bar chart representing mean values for soft tissue measurements of Class I and Class III patients on smiling 
Class III patients had $60 \%$ consonant smile arcs, $26.7 \%$ nonconsonant and $13.3 \%$ flat smile arcs which were found to be statistically insignificant between patients of both classes $(\mathrm{P}$-value $=0.095$, Effect size $=0.404)($ Figure 5 and Table 3).

Table (2): A comparison of soft tissue measurements between patients with Class I and III on smiling

\begin{tabular}{|c|c|c|c|c|c|c|c|c|c|}
\hline \multirow{2}{*}{$\begin{array}{l}\text { Measurement } \\
(\mathrm{mm})\end{array}$} & \multicolumn{2}{|c|}{$\begin{array}{c}\text { Class I } \\
(\mathrm{n}=15)\end{array}$} & \multicolumn{2}{|c|}{$\begin{array}{l}\text { Class III } \\
(\mathrm{n}=15)\end{array}$} & \multirow{2}{*}{$\begin{array}{c}\text { Mean } \\
\text { Difference } \\
(\mathrm{mm})\end{array}$} & \multicolumn{2}{|c|}{ 95\% CI for Difference } & \multirow{2}{*}{$P$-value } & \multirow{2}{*}{$\begin{array}{l}\text { Effect } \\
\text { size }(d)\end{array}$} \\
\hline & $\begin{array}{l}\text { Mean } \\
(\mathrm{mm})\end{array}$ & SD & $\begin{array}{l}\text { Mean } \\
(\mathrm{mm})\end{array}$ & $\mathrm{SD}$ & & $\begin{array}{l}\text { Lower } \\
\text { bound }\end{array}$ & $\begin{array}{l}\text { Upper } \\
\text { bound }\end{array}$ & & \\
\hline $\begin{array}{l}\text { Maxillary incisor } \\
\text { display }\end{array}$ & 9.67 & 1.52 & 9.13 & 2.16 & 0.54 & -0.86 & 1.93 & 0.441 & 0.289 \\
\hline Buccal corridors & 8.99 & 1.74 & 8.57 & 1.51 & 0.42 & -0.8 & 1.63 & 0.492 & 0.258 \\
\hline Gingival display & 3.20 & 2.15 & 1.03 & 2.31 & 2.17 & 0.5 & 3.83 & $0.008 *$ & $0.988^{\dagger}$ \\
\hline Smile width & 68.68 & 6.24 & 77.55 & 13.16 & -8.87 & -16.6 & -1.17 & $0.026 *$ & 0.861 \\
\hline
\end{tabular}

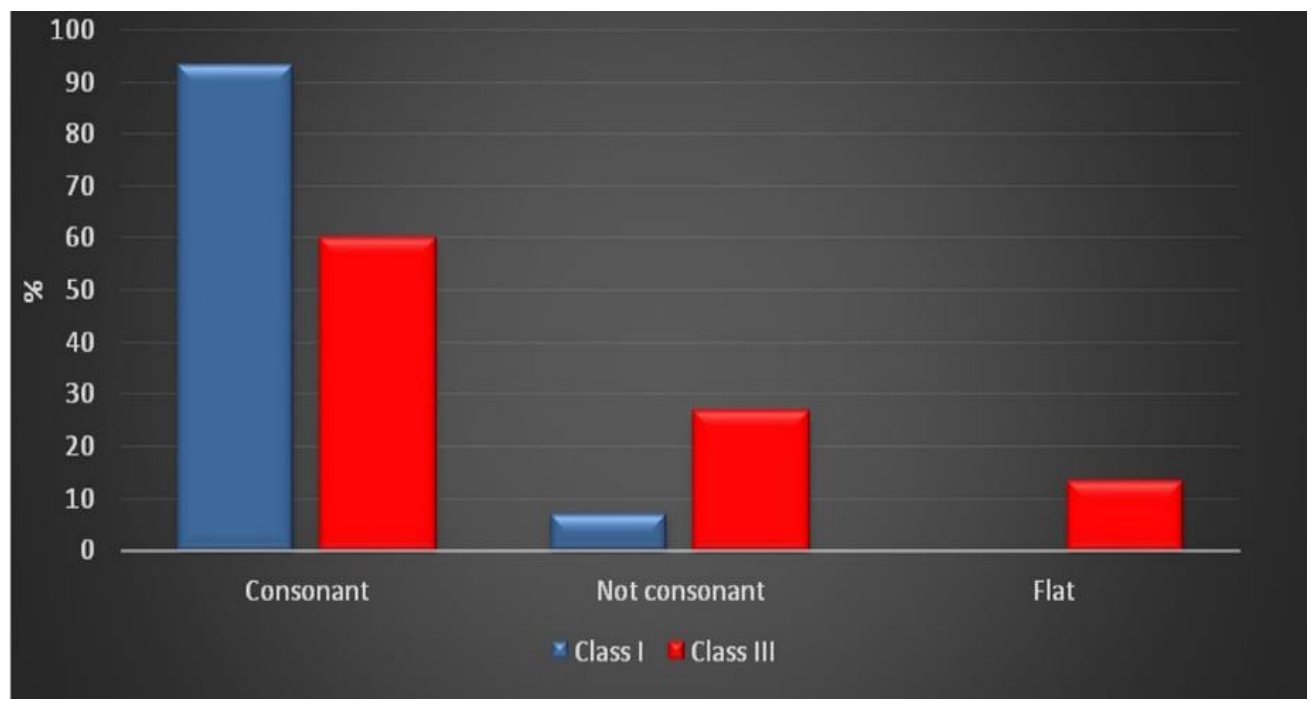

Fig. (5): Bar chart representing smile arc distribution of Class I and Class III patients

Table (3): A comparison between smile arcs of Class I and Class III patients on smiling

\begin{tabular}{|c|c|c|c|c|c|c|}
\hline & \multicolumn{2}{|c|}{$\begin{array}{c}\text { Class I } \\
(\mathrm{n}=15)\end{array}$} & \multicolumn{2}{|c|}{$\begin{array}{l}\text { Class III } \\
(\mathrm{n}=15)\end{array}$} & \multirow[t]{2}{*}{$P$-value } & \multirow{2}{*}{ Effect size (v) } \\
\hline & $\mathrm{n}$ & $\%$ & $\mathrm{~N}$ & $\%$ & & \\
\hline Consonant & 14 & 93.3 & 9 & 60 & & \\
\hline Not consonant & 1 & 6.7 & 4 & 26.7 & 0.095 & 0.404 \\
\hline \multirow[t]{2}{*}{ Flat } & 0 & 0 & 2 & 13.3 & & \\
\hline & \multicolumn{4}{|c|}{$*$ Significant at $P \leq 0.05$} & & \\
\hline
\end{tabular}




\section{DISCUSSION}

The present study seeks to determine the smile characteristics of skeletal Class III compared to skeletal I patient adult subjects. Two full face frontal photographs were taken for each participant at rest and with posed smile which is considered to be the most reproducible smile according to Ackerman et al [20] According to Mack [21] and Peck et al [22] the essential characteristic of the smile that influences esthetics is the quantity of maxillary gingival display. Hulsey [23] and Mackley [24] reported that the upper lip must be at the height of the gingival margin of the maxillary central incisors in an attractive smile. In addition, Ker et al [25] stated that the ideal value for smile esthetics was $2.1 \mathrm{~mm}$ of gingival display. In the present study, the gingival display for skeletal Class III patients was $1.03 \mathrm{~mm}$ which was found to be significantly less than that seen for Class I patients which was $3.2 \mathrm{~mm}$ indicating amount slightly more than the ideal amount of gingival display as reported by Chiche and Pinault [26] who pointed out that the esthetically perfect quantity of visible gingiva was about $1 \mathrm{~mm}$, but showed that $2-3 \mathrm{~mm}$ of gingiva might be esthetically satisfactory.

Although the upper lip length was notably longer for Class I relative to Class III patients, the gingival display was found to be greater in Class I patients which could be due to the significantly longer lower facial height shown for Class I relative to Class III patients in this study. According to Singer [27] \& Peck and Peck [22] those with gingival smiles were not only affected by the upper lip length however, they were influenced by vertical maxillary excess and greater muscular capacity to raise the lips. Although the intercommissure width at rest was found to be significantly wider for skeletal Class I patients, the smile width was found to be significantly wider for Class III patients which disagree with the results of Malhotra et al [16] who showed that subjects with Class I showed the maximum smile width. Abraham et al [28] reported a positive correlation between the lower facial height and smile width which was in contrast to the findings of the present study where Class III patients showed wider smile widths associated with reduced lower facial height. In the current study, Class III patients showed significantly longer chin height which could be due to the prognathic mandibular pattern found for skeletal Class III subjects. The impact of buccal corridors on smile esthetics was investigated by Gracco et al [29], Ker et al [25], and Martin et al [30] who concluded that large buccal corridors were considered less attractive. On the other hand, McNamara et al [31] and Roden-Johnson et al [32] and Sachdeva et al [33] did not find a connection between buccal corridors and smile esthetics. In the present study, the buccal corridor was found to be insignificantly different between both skeletal patterns which came in agreement with Malhotra et al [16] who pointed out that buccal corridors in Class III subjects did not influence the smile.

Sarver [34] focused on getting the perfect consonant smile arc which was illustrated by the curvature of the maxillary incisal edges being parallel to the curvature of the lower lip that was similar to the conception of Parekh et al [35]. Yoon et al [36] pointed out that a flat smile arc would noticeably decrease the attractiveness of smile. In the present study, non-consonant and flat smile arcs represented a higher percentage in Class III as compared to Class I patients however, it was statistically insignificant which was in agreement with Rashed and Heravi [15] who concluded that insignificant difference in smile arcs were found among all malocclusions. Badran and Mustafa [37] highlighted that a reverse and flat smile arc had a negative effect on the smile esthetics and that the clinician should avoid flat smile arcs to achieve esthetic smiles.

\section{CONCLUSION}

Digital Smile Design is a novel means for orthodontic treatment planning, particularly in multidisciplinary treatment. It strengthens diagnosis, enhances the inevitability of treatment and improves the communication among multidisciplinary team members. Findings from the present study shows that the smile components estimated from DSD are almost typical to those obtained from $\mathrm{CBCT}$, without exposure to radiation doses.

\section{REFERENCES}

[1] Springer N.C., Chang C., Fields H.W., et al. (2011) "Smile esthetics from the layperson's perspective", Am J Orthod Dentofacial Orthop., $139,91$.

[2] Toth E.K., Oliver D.R., Hudson J.M., Kim K.B.. (2016) "Relationships between soft tissues in a posed smile and vertical cephalometric skeletal measurements", Am J Orthod Dentofacial Orthop, 150,378 . 
[3] Simões D., Meyge de Brito G., Teixeira Cangussu M.C., Machado A.W., (2019) "Does the vertical position of maxillary central incisors in men influence smile esthetics perception?", Am. J. Orthod Dentofacial Orthop, 156, 485.

[4] Jih-Kuei Yeh and Chia-Hui Chen, (2018) "Estimated radiation risk of cancer from dental cone-beam computed tomography imaging in orthodontics patients", Oral Health, 18, 131.

[5] Benington P.C., Khambay B.S., Ayoub A.F., (2010) "An overview of three-dimensional imaging in dentistry", Dent Update, 37, 494.

[6] Haney E., Gansky S.A., Lee J.S., Johnson E., Maki K., Miller A.J., Huang J.C.. (2010) "Comparative analysis of traditional radiographs and cone-beam computed tomography volumetric images in the diagnosis and treatment planning of maxillary impacted canines". Am J Orthod Dentofac Orthop., 137, 590.

[7] Farman A.G., Scarfe W.C., (2009) "The basics of maxillofacial cone beam computed tomography" Semin Orthod., 15, 2.

[8] Roberts J., Drage N., Davies J., Thomas D., (2009) "Effective dose from cone beam CT examinations in dentistry, Br J Radiol. 82, 35.

[9] Al Najjar A., Colosi D., Dauer L.T., Prins R., Patchell G., Branets I., Goren A.D., Faber R.D., (2013) "Comparison of adult and child radiation equivalent doses from 2 dental cone-beam computed tomography units", Am J Orthod Dentofac Orthop., 143, 784.

[10] Pauels R., Beinsberger J., Collaert B., Theodorakou C., Rogers J., Walker A., Cockmartin L., Bosmans H., Jacobs R., Bogaerts R., (2012) "Effective dose range for dental cone beam computed tomography scanners", Eur J Radiol., 81, 267.

[11] Ludlow J.B., Walker C., (2013) "Assessment of phantom dosimetry and image quality of i-CAT FLX cone-beam computed tomography. Am J Orthod Dentofac Orthop., 144, 802.

[12] Lee C., Lee S.S., Kim J.E., Huh K.H., Yi W.J., Heo M.S., Choi S.C., (2016) "Comparison of dosimetry methods for panoramic radiography: thermoluminescent dosimeter measurement versus personal computer-based Monte Carlo method calculation. Oral Surg Oral Med Oral Pathol Oral Radiol., 121, 322.

[13] Soares M.R,, Batista W.O., de Lara Antonio P., Caldas L.V., Maia A.F., (2015) "Study of effective dose of various protocols in equipment cone beam CT", Appl Radiat Isot., 100, 21.

[14] Charavet C., Bernard J.C., Gaillard C., Gall MLe, (2019) "Benefits of Digital Smile Design (DSD) in the conception of a complex orthodontic treatment plan: a case report-proof of concept", Int Orthod, 17,573 .

[15] Rashed R. and Heravi F., (2010), "Lip-tooth relationships during smiling and speech: an evaluation of different malocclusion types", Aust Orthod J, 26, 153.

[16] Malhotra S., Sidhu M.S., Prabhakar M., Kochhar A.S., (2012), "Characterization of a posed smile and evaluation of facial attractiveness by panel perception and its correlation with hard and soft tissue", Orthodontics (Chic.), 13, 34.

[17] Kakadiya J., Pattnaik B., Kumari M, Vishnoi P. An Evaluation of smile in different malocclusion of local population-A pilot study. J Dental Medical Sciences 2015;14:25-32.

[18] Leonardi R., Annunziata A., Licciardello V., Barbato E., (2010) "Soft tissue changes following the extraction of premolars in nongrowing patients with bimaxillary protrusion", Angle Orthod, 80, 211.

[19] Khamis M.M., Abdelrehim A.A., (2019) "Interdisciplinary management of a patient with a gummy smile. J Oral Maxillofac Radiol 2019;7:3843.

[20] Ackerman J.L., Ackerman M.B., Brensinger C.M., Landis J.R., (1998) "A morphometric analysis of the posed smile", Clin Orthod Res., 1, 2.

[21] Mack M.R.. (1991), "Vertical dimension: a dynamic concept based on facial form and oropharyngeal function", Journal of Prosthetic Dentistry, 66, 478.

[22] Peck S., Peck L., Kataja M., (1992) "The gingival smile line", Angle Orthod., 62, 91.

[23] Hulsey C.M., (1970), "An esthetic evaluation of lip-teeth relationships present in the smile", Am J Orthod, 57, 132. 
[24] Mackley R.J., (1993) "An evaluation of smiles before and after orthodontic treatment", Angle Orthod 63, 183.

[25] Ker A.J., Chan R., Fields H.W., Beck M., Rosenstiel S., (2008), "Esthetics and smile characteristics from the layperson's perspective: a computer-based survey study", J Am Dent Assoc 139, 1318.

[26] Chiche, G. and Pinault, A. (2004), "Diagnosis and treatment planning of esthetic problems. In: Esthetics of anterior prosthodontics", Quintenessence, 13.

[27] Singer, R., (1974), "A study of the morphometric, treatment and esthetic aspects of gingival display", Am J Orthod, 65, 435.

[28] Abraham A., George J., Peter E., Philip K., Chankramamath R., Johnas D., Bhaskar A., (2015) "Establishment of a new relationship between posed smile width and lower facial height: A crosssectional study", European J Dentistry, 9, 394.

[29] Gracco A., Cozzani M., D’Elia L., Manfrini M., Peverada C.G.S., (2006), "The smile buccal corridors: aesthetic value for dentists and laypersons", Prog Orthod, 7, 56.

[30] Martin A.J., Buschang P.H., Boley J.C., Taylor R.W., McKinney T.W., (2007) "The impact of buccal corridors on smile attractiveness", Eur J Orthod, 29, 530.
[31] McNamara L., James A. McNamar, Jr, Ackerman M.B., Baccetti T., (2008) "Hard- and soft-tissue contributions to the esthetics of the posed smile in growing patients seeking orthodontic treatment", Am J Orthod Dentofacial Orthop, 133, 491.

[32] Roden-Johnson D., Gallerano R., English J., (2005), "The effects of buccal corridor spaces and arch form on smile esthetics", Am J Orthod Dentofacial Orthop., 127, 343.

[33] Sachdeva K., Singla A., Mahajan V., Jaj H.S., Negi A., (2012), "Esthetic and smile characteristics at rest and during smiling", J Ind Orthod Soc., 46, 17.

[34] Sarver D.M., (2001), "The importance of incisor positioning in the esthetic smile: the smile arc", Am J Orthod Dentofacial Orthop, 98, 111.

[35] Parekh S.M., Fields H.W., Beck M., Rosenstiel S., (2006), "Attractiveness of variations in the smile arc and buccal corridor space as judged by orthodontists and laymen", Angle Orthod., 76, 557.

[36] Yoon M., Jin T.H., Dong J.K., (1992), "A study on the smile in Korean youth", J Korean Acad Prosthodont, 30, 259.

[37] Badran S.A., Mustafa M., (2014), "Perception of smile attractiveness by laypeople-influence of profession and treatment experience", British J Medicine Medical Research, 4, 3777. 